\title{
Infecção aguda pelo HIV com apresentação clínica e laboratorial atípicas: relato de
}

\section{caso}

\author{
Acute HIV infection with atypical clinical and laboratory presentation: case report
}

Infección aguda por VIH con presentación clínica y de laboratorio atípica: reporte de caso

Larissa Silva Cyrino

ORCID: https://orcid.org/0000-0001-7620-960X Centro Universitário de Patos de Minas, Brasil

E-mail: larissa_scpm@hotmail.com

Bárbara Queiroz de Figueiredo

ORCID: https://orcid.org/0000-0003-1630-4597 Centro Universitário de Patos de Minas, Brasil

E-mail: barbarafigueiredo@unipam.edu.br

Célio Honório Lopes Júnior

ORCID: https://orcid.org/0000-0002-4549-2446

Centro Universitário Atenas, Brasil

E-mail: celiojunior1998@ outlook.com

Isadora Caixeta Marques

ORCID: https://orcid.org/0000-0002-6488-8745

Centro Universitário de Patos de Minas, Brasil

E-mail: dorys-22@hotmail.com

Luana Silva Cyrino

ORCID: https://orcid.org/0000-0002-7949-3607 Centro Universitário Atenas, Brasil

E-mail: luanasilvacyrino@outlook.com

Maria Fernanda Carbonaro Silva

ORCID: https://orcid.org/0000-0001-5400-7433

Centro Universitário Atenas, Brasil

E-mail: fefecarbonaro@hotmail.com

Maria Paula Pereira Lessa

ORCID: https://orcid.org/0000-0001-8587-3625

Centro Universitário Atenas, Brasil

E-mail: mariapaulalessa@gmail.com

Mauro Soares Marra

ORCID: https://orcid.org/0000-0002-0543-1569

Centro Universitário Atenas, Brasil

E-mail: maurosoaresm@gmail.com

Stéfani do Vale

ORCID: https://orcid.org/0000-0002-5211-9834

Centro Universitário Atenas, Brasil

E-mail: stefani.vale@hotmail.com

Bruno César de Oliveira Pires

ORCID: https://orcid.org/0000-0003-2747-3839

Hospital Nossa Senhora de Fátima, Brasil E-mail: bruno_ces@ibest.com.br

\section{Resumo}

Introdução: A infecção pelo vírus da imunodeficiência humana (HIV) representa, no Brasil e no mundo, um problema de saúde pública: as estimativas mostram que, em 2017, foram diagnosticados no Brasil 42.420 novos casos de HIV. Apesar dessas altas taxas, nota-se que o subdiagnóstico ainda é um problema: dados apontam que, nos Estados Unidos, quase $15 \%$ das pessoas infectadas pelo vírus HIV desconhecem esse diagnóstico. Objetivo: relatar um caso atípico de infecção aguda pelo HIV, descrevendo sua evolução clínica e laboratorial até que o diagnóstico fosse confirmado, além de evidenciar a importância da suspeição clínica nos casos em que o quadro clínico é incomum e os exames sorológicos iniciais não são definitivos para diagnóstico. Metodologia: trata-se de um estudo de caso clínico com perspectiva qualitativa e descritiva, que consiste em uma pesquisa em que, em geral, ocorre com coleta direta de dados, cujo o pesquisador é o instrumento indispensável. Relato de caso: paciente do sexo feminino, 20 anos, diagnosticada com HIV. Não manifestou alguns dos principais sinais e sintomas mais comuns, tais como astenia, faringite e erupções cutâneas evidenciando, por outro lado, fenômenos relacionados ao comprometimento acentuado do fígado, com hepatite laboratorial significativa, o que não é corriqueiro. Conclusão: 
o diagnóstico e a implementação da terapia anti retroviral (TAR) precoces colaboram com a obtenção de resultados terapêuticos favoráveis: consegue-se uma longa supressão viral, preservação e até mesmo aumento das funções imunitárias e a conservação de uma população viral mais homogênea.

Palavras-chave: HIV; Sorologia; Epidemiologia; Diagnóstico.

\begin{abstract}
Introduction: Infection with the human immunodeficiency virus (HIV) represents, in Brazil and in the world, a public health problem: estimates show that, in 2017, 42,420 new cases of HIV were diagnosed in Brazil. Despite these high rates, it is noted that underdiagnosis is still a problem: data show that, in the United States, almost $15 \%$ of people infected with the HIV virus are unaware of this diagnosis. Objective: to report an atypical case of acute HIV infection, describing its clinical and laboratory evolution until the diagnosis was confirmed, in addition to highlighting the importance of clinical suspicion in cases where the clinical picture is uncommon and the initial serological tests are not definitive for diagnosis. Methodology: this is a clinical case study with a qualitative and descriptive perspective, which consists of a research that, in general, takes place with direct data collection, in which the researcher is the indispensable instrument. Case report: female patient, 20 years old, diagnosed with HIV. It did not manifest some of the most common main signs and symptoms, such as asthenia, pharyngitis and skin rashes, evidencing, on the other hand, phenomena related to severe liver involvement, with significant laboratory hepatitis, which is not common. Conclusion: early diagnosis and implementation of antiretroviral therapy (ART) collaborate with the achievement of favorable therapeutic results: it achieves a long viral suppression, preservation and even increase of immune functions and the conservation of a more homogeneous viral population.
\end{abstract}

Keywords: HIV; Serology; Epidemiology; Diagnosis.

\title{
Resumen
}

Introducción: La infección por el virus de la inmunodeficiencia humana (VIH) representa, en Brasil y en el mundo, un problema de salud pública: las estimaciones muestran que, en 2017, se diagnosticaron 42.420 nuevos casos de VIH en Brasil. A pesar de estas altas tasas, se observa que el infradiagnóstico sigue siendo un problema: los datos muestran que, en Estados Unidos, casi el 15\% de las personas infectadas por el virus del VIH desconocen este diagnóstico. Objetivo: reportar un caso atípico de infección aguda por VIH, describiendo su evolución clínica y de laboratorio hasta la confirmación del diagnóstico, además de resaltar la importancia de la sospecha clínica en los casos en los que el cuadro clínico es poco común y las pruebas serológicas iniciales no son definitivas para el diagnóstico. . Metodología: se trata de un estudio de caso clínico con perspectiva cualitativa y descriptiva, que consiste en una investigación que, en general, se realiza con recolección directa de datos, en la que el investigador es el instrumento indispensable. Caso clínico: paciente de 20 años diagnosticada de VIH. No manifestó algunos de los principales signos y síntomas más comunes, como astenia, faringitis y erupciones cutáneas, evidenciándose, por otro lado, fenómenos relacionados con afectación hepática severa, con hepatitis de laboratorio importante, que no es común. Conclusión: el diagnóstico precoz y la implementación de la terapia antirretroviral (ART) colaboran con el logro de resultados terapéuticos favorables: logra una supresión viral prolongada, preservación e incluso aumento de las funciones inmunes y la conservación de una población viral más homogénea.

Palabras clave: VIH; Serología; Epidemiología; Diagnóstico.

\section{Introdução}

A infecção pelo vírus da imunodeficiência humana (HIV) representa, no Brasil e no mundo, um problema de saúde pública: as estimativas mostram que, em 2017, foram diagnosticados no Brasil 42.420 novos casos de HIV, com uma taxa de detecção de 18,3/100.000 habitantes. Além disso, sabe-se que no período de 1980 a junho de 2018, 982.129 casos de aids foram detectados no país (Saúde, 2018). Apesar dessas altas taxas, nota-se que o subdiagnóstico ainda é um problema: dados apontam que, nos Esatdos Unidos, quase 15\% das pessoas infectadas pelo vírus HIV desconhecem esse diagnóstico (Bartlett et al. 2018). Organizando os dados do Brasil por sexo e faixa etária, percebe-se que, em 2017, dos 42420 casos de HIV diagnosticados, 30659 eram no sexo masculino, no qual a faixa etária de maior notificação foi dos 20 aos 24 anos. Enquanto isso, o número referente ao sexo feminino foi de 11753 casos, dentre os quais a faixa etária mais significativa foi dos 25 aos 29 anos (Saúde, 2018).

A história natural da doença é marcada por 3 fases: infecção aguda, latência clínica e fase sintomática, esta última caracterizando a evolução para Aids (síndrome da imunodeficiência adquirida) (Saúde, 2018). O intervalo de tempo entre a infecção e o aparecimento da doença é bastante variável, podendo chegar a 10 anos ou mais. A infecção aguda pelo HIV se dá entre duas e seis semanas após o contágio e os sintomas podem ser brandos ou proeminentes, porém são inespecíficos, o que 
dificulta a suspeição do HIV. Dentre as manifestações mais comuns, destacam-se astenia, febre, adenomegalia, faringite, erupções cutâneas e mialgia e artralgia (Vilar et al. 2008). No entanto, há relatos de casos com apresentações atípicas, tais como meningite asséptica, síndrome de Guillan-Barré e manifestações relacionadas ao comprometimento do fígado e do pâncreas (Saúde, 2018).

A inespecificidade dos sinais e sintomas, associada à existência de uma janela imunológica, ou seja, um intervalo de tempo entre o contágio e a detecção de marcadores da infecção pelo HIV, faz com que o diagnóstico da doença seja, muitas vezes, dificultado. Nos últimos anos, novos testes surgiram com o intuito de permitir o diagnóstico precoce; enquanto os imunoensaios de primeira geração possuem uma janela de soroconversão de aproximadamente 6 a 8 semanas, os de quarta geração têm esse tempo reduzido para, em média, 15 dias. Já os exames que pesquisam material genético do HIV, em vez de anticorpos, são capazes de diagnosticar a infecção mais precocemente (Saúde, 2018).

Em se tratando de locais de difícil acesso ou sem infraestrutura laboratorial, de populações vulneráveis e de outras situações específicas, o diagnóstico é feito, prioritariamente, por meio do teste rápido, em que pode ser utilizado fluido oral, bem como soro, plasma ou sangue total. Porém, para testes rápidos, a janela imunológica pode ser maior, de até três meses, o que pode resultar em falhas de diagnóstico (Brasil, 2015). O objetivo desse estudo é relatar um caso atípico de infecção aguda pelo HIV, descrevendo sua evolução clínica e laboratorial até que o diagnóstico fosse confirmado, além de evidenciar a importância da suspeição clínica nos casos em que o quadro clínico é incomum e os exames sorológicos iniciais não são definitivos para diagnóstico.

\section{Metodologia}

Este artigo trata-se de um estudo de caso clínico com perspectiva qualitativa e descritiva, que consiste em uma pesquisa em que, em geral, ocorre com coleta direta de dados, cujo o pesquisador é o instrumento indispensável. O presente estudo contou com o aporte de trabalhos acadêmicos entre os anos de 1999 e 2019. Por meio do acesso às principais bases de dados, a saber: dados National Library of Medicine (PubMed MEDLINE), Scientific Electronic Library Online (Scielo), Cochrane Database of Systematic Reviews (CDSR), Google Scholar, Biblioteca Virtual em Saúde (BVS) e EBSCO Information Services, no período compreendido entre janeiro e março de 2019. O Termo de Consentimento Livre e Assistido (TCLE) foi assinado pelo paciente para coleta de dados neste estudo, e obteve-se aprovação do Comitê de Ética em Pesquisa do Centro Universitário de Patos de Minas (UNIPAM).

\section{Relato de Caso}

Paciente do sexo feminino, 20 anos de idade, internada com história de 10 dias de febre, mialgia, dor abdominal em hipocôndrio direito e cefaleia temporal. Negava diarreia, vômitos, odinofagia, tosse e coriza. Referia lazer em zona rural uma semana antes do início dos sintomas. Negava outras viagens recentes. Negava etilismo, tabagismo e drogadição. Em uso de dipirona para febre, negando uso de paracetamol ou antiinflamatórios.

Ao exame físico, não apresentava nenhuma alteração clínica. Exames laboratoriais com elevação de transaminases hepáticas, com TGP de 462 (normal 9-52 U/L) e TGO 338 U/L (normal 14-36 U/L); GamaGT, Fosfatase Alcalina e Bilirrubinas dentro dos limites da normalidade. No hemograma, observou-se Anemia Normocítica e Normocrômica, com Hemoglobina (Hb) de 9,2 g/dL, com leucometria de $8.200 / \mathrm{mm}^{3}$ e plaquetas de $335.000 / \mathrm{mm}^{3}$ ). Urina rotina tipo $1 \mathrm{com}$ hematúria microscópica. TC de abdome com nódulo em região anexial esquerda, compatível com teratoma, sem visceromegalias. 
Esteve internada por 4 dias, em observação clínica, e evoluiu com resolução dos sintomas, apenas com tratamento sintomático, recebendo alta com hipótese diagnóstica de dengue não complicada. Sorologia para dengue em andamento. Orientada a realizar seguimento na atenção primária.

Após 2 semanas, houve recidiva da febre e paciente foi reinternada. Exames da internação passada haviam descartado dengue (IgG e IgM negativos). Queixando-se de febre e vômitos com 5 dias de evolução, além de perda de peso de 4 Kg desde o início do quadro e dor intensa em joelhos há 5 dias. Ao exame físico, estava desidratada, descorada e ictérica +/4+; não havia lesões na pele, linfonodomegalia ou alterações na orofaringe. Exame físico abdominal e cardiopulmonar sem alerações. Dor à palpação em joelhos, mas sem sinais flogísticos.

Exames complementares realizados na Unidade de Pronto-Atendimento do município um dia antes da reinternação mostravam Hb de 10,1, leucócitos totais de 1950, linfócitos totais de 527, $1 \%$ de linfócitos atípicos e plaquetas de 230000. TGP de 560, TGO de 560, Bilirrubinas totais de 1,9, Bilirrubina Direta de 1,84, Bilirrubina Indireta de 0,06 e amilase de 53. Decidido por aprofundar investigação, sendo solicitados diversos exames laboratoriais (Quadro 1). Além disso, realizou nova tomografia computadorizada de abdome, que continuou mostrando apenas o nódulo em região anexial esquerda, compatível com teratoma, sem visceromegalias ou outras alterações. Realizou radiografia de ambos os joelhos, sem alterações radiológicas.

Quadro 1: Exames laboratoriais à admissão da segunda internação.

\begin{tabular}{|c|c|c|}
\hline EXAME & RESULTADO & VALOR DE REFERÊNCIA \\
\hline Hemoglobina & $10,6 \mathrm{~g} / \mathrm{dL}$ & 12,0 a $16,6 \mathrm{~g} \%$ \\
\hline VCM & $79,0 \mathrm{fl}$ & 80 a $100 \mathrm{fl}$ \\
\hline $\mathrm{HCM}$ & $25,9 \mathrm{pg}$ & 26 a $34 \mathrm{pg}$ \\
\hline Leucócitos totais & $3.000 / \mathrm{mm}^{3}$ & 5,5 a $10 \mathrm{mil} / \mathrm{mm}^{3}$ \\
\hline Neutrófilos & $2.220 / \mathrm{mm}^{3}(74 \%)$ & 1.800 a $7.000(40-80)$ \\
\hline Linfócitos & $690 / \mathrm{mm}^{3}(23 \%)$ & 1.000 a $4.800(20-50)$ \\
\hline Plaquetas & $178.000 / \mathrm{mm}^{3}$ & 150.000 a $350.000 / \mathrm{mm}^{3}$ \\
\hline Proteína C Reativa & $5 \mathrm{mg} / \mathrm{L}$ & Inferior a $10,0 \mathrm{mg} / \mathrm{L}$ \\
\hline Velocidade de hemossedimentação & $50 \mathrm{~mm}$ & 0 a $20 \mathrm{~mm}$ em 60 minutos \\
\hline Ferritina & 313 nanog $/ \mathrm{ml}$ & 10 a 291 nanog $/ \mathrm{ml}$ \\
\hline TGO & $560 \mathrm{U} / \mathrm{L}$ & 14 a $36 \mathrm{U} / \mathrm{L}$ \\
\hline TGP & $851 \mathrm{U} / \mathrm{L}$ & 9 a $52 \mathrm{U} / \mathrm{L}$ \\
\hline Gama GT & $677 \mathrm{U} / \mathrm{L}$ & 12 a $43 \mathrm{U} / \mathrm{L}$ \\
\hline Fosfatase Alcalina & $132 \mathrm{U} / \mathrm{L}$ & 38,0 a $126,0 \mathrm{U} / \mathrm{L}$ \\
\hline Bilirrubinas totais & $1,20 \mathrm{mg} / \mathrm{dL}$ & 0,2 a $1,3 \mathrm{mg} / \mathrm{dL}$ \\
\hline Bilirrubina direta & $1,10 \mathrm{mg} / \mathrm{dL}$ & 0,0 a $0,3 \mathrm{mg} / \mathrm{dL}$ \\
\hline Bilirrubina indireta & $0,10 \mathrm{mg} / \mathrm{dL}$ & 0,0 a $1,1 \mathrm{mg} / \mathrm{dL}$ \\
\hline TAP & $100,0 \%$ & $70 \%$ a $100 \%$ \\
\hline Albumina & $0,0 \mathrm{~g} / \mathrm{dL}$ & 3,5 a $5,0 \mathrm{~g} / \mathrm{dL}$ \\
\hline Amilase & $42 \mathrm{U} / \mathrm{L}$ & 30 a $110 \mathrm{U} / \mathrm{L}$ \\
\hline Lipase & $116 \mathrm{U} / \mathrm{L}$ & 23 a $300 \mathrm{U} / \mathrm{L}$ \\
\hline Desidrogenase lática & $1.064,0 \mathrm{U} / \mathrm{L}$ & 316 a $618 \mathrm{U} / \mathrm{L}$ \\
\hline Uréia & $13 \mathrm{mg} / \mathrm{dL}$ & 15,0 a $36,4 \mathrm{mg} / \mathrm{dL}$ \\
\hline Creatinina & $0,5 \mathrm{mg} / \mathrm{dL}$ & 0,5 a $1,0 \mathrm{mg} / \mathrm{dL}$ \\
\hline TSH & $1,25 \mathrm{microUI} / \mathrm{ml}$ & 0,35 a $4,94 \mathrm{microUI} / \mathrm{ml}$ \\
\hline T4 livre & $0,9 \mathrm{ng} / \mathrm{dl}$ & 0,79 a $1,86 \mathrm{ng} / \mathrm{dl}$ \\
\hline B-HCG & $<1.20 \mathrm{mUI} / \mathrm{ml}$ & Grávida - Acima de 100 mUI/ml \\
\hline Toxoplasmose IgM & 0,09 & Reagente - Superior a 1,5 \\
\hline
\end{tabular}


Research, Society and Development, v. 10, n. 10, e325101019016, 2021

(CC BY 4.0) | ISSN 2525-3409 | DOI: http://dx.doi.org/10.33448/rsd-v10i10.19016

\begin{tabular}{|c|c|c|}
\hline Toxoplasmose IgG & $0,2 \mathrm{IU} / \mathrm{ml}$ & Reagente - Superior a $3 \mathrm{IU} / \mathrm{ml}$ \\
\hline Citomegalovírus IgM & $0,31 \mathrm{AU} / \mathrm{ml}$ & Reagente $-\geq 1,00 \mathrm{AU} / \mathrm{ml}$ \\
\hline Citomegalovírus IgG & $75,8 \mathrm{AU} / \mathrm{ml}$ & Reagente - Superior a $6,6 \mathrm{AU} / \mathrm{ml}$ \\
\hline Epstein-Baar vírus IgM & $10 \mathrm{U} / \mathrm{ml}$ & Reagente $-\geq 40 \mathrm{U} / \mathrm{ml}$ \\
\hline Epstein-Baar vírus IgG & $159 \mathrm{U} / \mathrm{ml}$ & Reagente $-\geq 20 \mathrm{U} / \mathrm{ml}$ \\
\hline VDRL & Não reativo & Não reativo \\
\hline FTA-ABS IgM & Não reagente & Não reagente \\
\hline FTA-ABS IgG & Não reagente & Não reagente \\
\hline HBsAg & $0,21 \mathrm{~S} / \mathrm{CO}$ & Reagente - Superior a 2,5 S/CO \\
\hline Anti-HBc IgM & Não reagente & Não reagente \\
\hline Anti-HBc IgG & Não reagente & Não reagente \\
\hline Anti-HBs & $350,32 \mathrm{mUI} / \mathrm{mL}$ & Reagente - superior a $10 \mathrm{mUI} / \mathrm{mL}$ \\
\hline Anti-HCV & $0,11 \mathrm{~S} / \mathrm{CO}$ & Reagente - superior a 2,5 S/CO \\
\hline Anti-HAV IgM & Não reagente & Não reagente \\
\hline Anti-HAV IgG & Não reagente & Não reagente \\
\hline Anti-HIV & Reagente $-7,88 \mathrm{~S} / \mathrm{CO}$ & Reagente $-\geq 2,5 \mathrm{~S} / \mathrm{CO}$ \\
\hline Teste rápido 1 anti-HIV (imunocromatografia) & Não reagente & Não reagente \\
\hline Teste rápido 2 anti-HIV (imunocromatografia) & Não reagente & Não reagente \\
\hline Western-Blot HIV & Negativo & $\begin{array}{c}\text { Presença de no mínimo duas bandas dentre } \\
\text { gp120 e/ou gp } 160 \\
\text { gp } 41 \text { e p24 }\end{array}$ \\
\hline Leptospirose IgM & Não reagente & Não reagente \\
\hline Dengue IgM & Não reagente & Não reagente \\
\hline Dengue IgG & Não reagente & Não reagente \\
\hline FTA-ABS IgM & Não reagente & Não reagente \\
\hline FTA-ABS IgG & Não reagente & Não reagente \\
\hline HBsAg & $0,21 \mathrm{~S} / \mathrm{CO}$ & Reagente - Superior a 2,5 S/CO \\
\hline Anti-HBc IgM & Não reagente & Não reagente \\
\hline Anti-HBc IgG & Não reagente & Não reagente \\
\hline Anti-HBs & $350,32 \mathrm{mUI} / \mathrm{mL}$ & Reagente - superior a $10 \mathrm{mUI} / \mathrm{mL}$ \\
\hline Anti-HCV & $0,11 \mathrm{~S} / \mathrm{CO}$ & Reagente - superior a 2,5 S/CO \\
\hline Anti-HAV IgM & Não reagente & Não reagente \\
\hline Anti-HAV IgG & Não reagente & Não reagente \\
\hline Anti-HIV & Reagente $-7,88 \mathrm{~S} / \mathrm{CO}$ & Reagente $-\geq 2,5 \mathrm{~S} / \mathrm{CO}$ \\
\hline Teste rápido 1 anti-HIV (imunocromatografia) & Não reagente & Não reagente \\
\hline Teste rápido 2 anti-HIV (imunocromatografia) & Não reagente & Não reagente \\
\hline Western-Blot HIV & Negativo & $\begin{array}{c}\text { Presença de no mínimo duas bandas dentre } \\
\text { gp120 e/ou gp } 160 \\
\text { gp } 41 \text { e p24 }\end{array}$ \\
\hline Leptospirose IgM & Não reagente & Não reagente \\
\hline Dengue IgM & Não reagente & Não reagente \\
\hline Dengue IgG & Não reagente & Não reagente \\
\hline Anticorpos antinucleares (FAN) & Não reagente & Não reagente \\
\hline Anticorpos anti-SM & $<7 \mathrm{U} / \mathrm{ml}$ & Reagente - Superior a $25 \mathrm{U} / \mathrm{ml}$ \\
\hline Anticorpo anti-mitocôndria (AMA) & Negativo & Negativo \\
\hline p-ANCA & Negativo & Negativo \\
\hline c-ANCA & Negativo & Negativo \\
\hline Imunoglobulina IgG & $1623.3 \mathrm{mg} / \mathrm{dl}$ & 552 a $1631 \mathrm{mg} / \mathrm{dl}$ \\
\hline CA-125 & $18,30 \mathrm{U} / \mathrm{ml}$ & $\leq 35 \mathrm{U} / \mathrm{ml}$ \\
\hline Alfafetoproteína & $9,8 \mathrm{ng} / \mathrm{ml}$ & Até $9 \mathrm{ng} / \mathrm{ml}$ \\
\hline
\end{tabular}

Fonte: Autores (2021). 
Diante da informação do resultado reagente do anti-HIV (7,88 S/CO; valor de referência: reagente - $\geq 2,5 \mathrm{~S} / \mathrm{CO}$ ), foram realizados dois testes rápidos imunocromatográficos, de dois fabricantes diferentes, sendo ambos não reagentes. Em seguida, obteve-se resultado de Western-Blot para HIV também com resultado negativo, sem detecção de anticorpos contra os antígenos p24, p31, gp 120, gp41 e gp36. Durante a internação, a paciente evoluiu com um pico diário de febre por 10 dias consecutivos, de até $38,5^{\circ} \mathrm{C}$ graus. Evoluiu com artrite assimétrica de ambos os joelhos, com intenso edema e aumento de temperatura bilateralmente, principalmente à direita, sendo iniciado cetoprofeno, com melhora gradativa dos sinais de artrite e da queixa clínica de dor.

Após 17 dias de internação, a paciente apresentava boa evolução, sem febre por 7 dias, resolução da artrite em joelhos, sem queixas clínicas, recebendo alta hospitalar. Realizada suspeita clínica de infecção aguda pelo HIV, sendo a paciente encaminhada ao ambulatório microrregional de HIV/Aids para seguimento e investigação. No serviço de Infectologia, 21 dias após a alta, foram realizados dois testes rápidos pra HIV com resultado reagente. O PCR quantitativo para HIV mostrou carga viral de 170.831 cópias (log 5,23), confirmando a infecção pelo HIV. A contagem de linfócitos CD4 foi de 478. A paciente encontrava-se sem queixas clínicas e foi iniciado o tratamento com antirretrovirais com Lamivudina/Tenofovir/Efavirenz.

\section{Discussão}

No presente trabalho, foi apresentado um caso de infecção aguda pelo HIV em paciente do sexo feminino e 20 anos de idade, o que remete a um quadro epidemiológico menos comum, no que se refere ao gênero, fato que pode dificultar a suspeição clínica da doença, sobretudo quando não há epidemiologia bem caracterizada para o risco, como no caso descrito. Esse panorama é retratado por meio do seguinte dado: entre 2007 e junho de 2018, de fato, a maior parte dos casos novos de infecção pelo HIV no Brasil deu-se entre 20 e 34 anos, com 52,6\% dos casos, mostrando que os adultos jovens constituem o principal grupo com diagnóstico novo da doença no País. Por outro lado, a razão de sexos vem aumentando pelo menos desde 2007, quando era de 1,4, chegando a 2,6 em 2017, o que mostra que os casos novos têm se concentrado cada vez mais em homens (Saúde, 2018).

Além disso, outro aspecto importante a se destacar é a atipicidade do quadro clínico retratado. Isso porque a paciente não manifestou alguns dos principais sinais e sintomas mais comuns, tais como astenia, faringite e erupções cutâneas (Brasil, 2019) evidenciando, por outro lado, fenômenos relacionados ao comprometimento acentuado do fígado, com hepatite laboratorial significativa, o que não é corriqueiro (Saúde, 2018). Segundo o Protocolo Clínico e Diretrizes Terapêuticas para Manejo da Infecção pelo HIV, os sinais e sintomas mais comuns da infecção aguda são febre, cefaléia, astenia, adenopatia, faringite, exantema e mialgia (Saúde, 2018) e a paciente apresentou apenas parte dessa sintomatologia.

Diante das sorologias negativas para hepatites virais, da não utilização de medicamentos hepatotóxicos previamente e da ausência de outros fatores de risco que pudessem sugerir demais etiologias para o dano hepático, se consolida a hipótese de que a hepatite aguda resultou da própria infecção aguda pelo HIV. Isso indica que, em pacientes com comprometimento hepático agudo, a infecção aguda pelo HIV deve ser um diagnóstico diferencial a ser considerado. Não foram encontrados outros relatos de casos na literatura com descrição de HIV agudo acompanhado de elevação significativa de transaminases, acima de 10 vezes o limite superior de normalidade, como observado neste caso. $\mathrm{O}$ acometimento do fígado é raro na síndrome retroviral aguda (Saúde, 2018).

Vale ressaltar que a hepatite $\mathrm{C}$ possui vias comuns de transmissão com a infecção pelo vírus HIV, podendo também elevar as transaminases. Além disso, sabe-se que a detecção laboratorial dos anticorpos anti-HCV pode demorar até 4 meses desde o contato com o patógeno. Devido a esses fatores, a sorologia para hepatite $\mathrm{C}$ foi repetida no seguimento ambulatorial da paciente do caso, permanecendo negativa, o que afastou definitivamente o diagnóstico dessa infecção. 
Ademais, percebe-se a ocorrência da chamada "artrite reativa", em que, após a exposição a um antígeno, a resposta imune do hospedeiro desencadeia uma artrite transitória, que pode ser acompanhada ou não de outras manifestações, como uretrite e conjuntivite, caracterizando a Síndrome de Reiter (Brasil, 2015). Dentre os estudos escassos em que a infecção pelo HIV é relacionada à artrite reativa, um deles foi realizado com 270 pacientes portadores de HIV, dentre os quais 21 apresentaram esse quadro, sendo que, dentre eles, a maior parte (47\%) demonstrou acometimento de duas a quatro articulações (acometimento oligoarticular) (Berman et al., 1999). Porém, esse estudo não menciona se a amostra foi analisada na fase aguda ou na fase crônica da infecção pelo HIV. De forma geral, o padrão de envolvimento articular associado à infecção pelo HIV é semelhante ao de outros quadros virais, com início agudo, curta duração e ausência de recidivas ou de alterações erosivas. Chinniah et al (2005) descrevem que manifestações articulares têm sido descritas em qualquer estágio da infecção pelo HIV, mas tendem a ser mais prevalentes nos estágios avançados.

Outro aspecto interessante é que a infecção aguda pelo HIV é uma das doenças que pode se apresentar como a chamada "Síndrome Mononucleose Like", definida como uma doença febril aguda com linfocitose e presença de linfócitos atípicos. Destaca-se que outros agentes infecciosos também podem cursar com a síndrome, como o vírus Epstein-Barr (EBV) e o Citomegalovirus (CMV), dentre outros. No caso da infecção aguda pelo HIV, além das alterações laboratoriais mencionadas anteriormente, adenomegalia e faringite são os principais achados (Ferreira et al. 2018). No caso descrito, a paciente não apresentou nenhum dos sinais acima, tanto clínicos quanto laboratoriais; pelo contrário: cursou com uma linfopenia, o que poderia ter precipitado a ocorrência de infecções oportunistas. Há relatos na literatura, por exemplo, de casos de Pneumocistose na infecção aguda pelo HIV (Ungprasert et al. 2013).

De forma interessante, as manifestações da infecção aguda pelo HIV distribuíram-se em duas fases, com um intervalo de cerca de 14 dias de remissão dos sintomas. Devido ao fato de que, inicialmente, não houve suspeita de infecção pelo HIV, não se sabese a primeira fase sintomática (com febre, mialgia, cefaleia e alteração de transaminases) resultou da infecção pelo HIV. Porém, na segunda fase (com febre, artrite e alteração de transaminases), foi feita investigação para inúmeras etiologias e encontrou-se apenas o HIV agudo como diagnóstico. Assim, devido à soroconversão documentada, levanta-se a hipótese de que todo o quadro clínico resultou da infecção aguda pelo HIV. No entanto, não se encontrou descrição desse tipo de evolução clínica na literatura.

Com relação ao diagnóstico, ficou explícita a limitação do teste de Western Blot para diagnóstico da infecção aguda pelo HIV, já que o exame da paciente foi negativo, sem anticorpos contra nenhum antígeno do HIV. Esse exame só irá revelar uma amostra reagente após decorridos pelo menos 30 dias desde a exposição ao vírus. Além disso, nota-se também a limitação dos testes rápidos para diagnóstico da infecção recente, quando comparados com os ensaios de quarta geração. Isso porque a paciente do caso realizou dois testes rápidos, sendo que ambos os resultados foram negativos. Sabe-se que os testes rápidos podem demorar até 60 dias para positivar, enquanto o anti-HIV de quarta geração pode vir positivo após 22 dias de exposição (Saúde, 2018).

\section{Considerações Finais}

Assim, diante da suspeita clínica de HIV agudo, faz-se necessário manter a hipótese diagnóstica e persistir na investigação, afim de descartar definitivamente a doença ou de diagnosticá-la o mais cedo possível. A estratégia mais recomendada é a realização de um teste molecular, com detecção de RNA ou DNA pró-viral, cuja positividade é esperada a partir de 10 dias da infecção, permitindo diagnóstico precoce caso o resultado esteja acima de 5.000 cópias/mL (Saúde, 2018).

Sabe-se que o diagnóstico e a implementação da terapia anti retroviral (TAR) precoces colaboram com a obtenção de resultados terapêuticos favoráveis: consegue-se uma longa supressão viral, preservação e até mesmo aumento das funções imunitárias e a conservação de uma população viral mais homogênea. Além disso, uma das principais vantagens do uso 
Research, Society and Development, v. 10, n. 10, e325101019016, 2021

(CC BY 4.0) | ISSN 2525-3409 | DOI: http://dx.doi.org/10.33448/rsd-v10i10.19016

precoce da TAR é interrupção da cadeia de transmissão do vírus, possibilitada pela supressão da carga viral, que torna o indivíduo incapaz de transmitir o vírus HIV (Loreto et al. 2012).

\section{Referências}

Bartlett, J. G. \& Sax, P. (2016). Screening and diagnostic testing for HIV infection. UpToDate. Waltham, MA.

Berman, A., Cahn, P., Spindler, U., Lucero, E., Paz, S. \& Espinoza, L. R. (1999). Human immunodeficiency virus infection associated arthritis: clinical characteristics. Journal Of Rheumatology. 26 (5), 1158-1162.

Brasil. Ministério da Saúde. Secretaria de Vigilância em Saúde. (2019). Coordenação-Geral de Desenvolvimento da Epidemiologia em Serviços. Guia de Vigilância em Saúde: volume único [recurso eletrônico] / Ministério da Saúde, Secretaria de Vigilância em Saúde, Coordenação-Geral de Desenvolvimento da Epidemiologia em Serviços. Ministério da Saúde.

Chinniah, K., Mody, G. M., Bhimma, R. \& Adhikari, M. (2005). Arthritis in association with human immunodeficiency virus infection in Black African children: causal or coincidental? Rheumatology, 44 (7), 915-920.

Ferreira, L; S., Conto, B. F., \& Narvaez, G. A. (2018). Síndromes de Mononucleose. <http://docs.bvsalud.org/biblioref/2018/04/882328/sindromes-demononucleose.pdf>.

Loreto, S. \& Pereira, J. M. A. (2012). A infecção por HIV - importância das fases iniciais e do diagnóstico precoce. Acta Farmacêutica Portuguesa, 2 (1), 517.

Ministério da Saúde. (2018). Manual técnico para o diagnóstico da infecção pelo HIV em adultos e crianças.

Portaria SAS/MS n 1150. (2015). Protocolo Clínico e Diretrizes Terapêuticas: Artrite Reativa - Doença de Reiter. 11 de novembro de 2015.

Secretaria de Vigilância em Saúde (2018). Departamento de Vigilância, Prevenção e Controle das Infecções Sexualmente Transmissíveis, do HIV/Aids e das Hepatites Virais. Protocolo clínico e diretrizes terapêuticas para manejo da infecção pelo hiv em adultos.

Secretaria de Vigilância em Saúde (2018). Departamento de Vigilância, Prevenção e Controle das Infecções Sexualmente Transmissíveis, do HIV/Aids e das Hepatites Virais. Protocolo clínico e diretrizes terapêuticas para manejo da infecção pelo hiv em adultos.

Secretaria de Vigilância em Saúde (2018). Ministério da Saúde. Boletim Epidemiológico HIV/AIDS.

Secretaria de Vigilância em Saúde Departamento de DST, Aids e Hepatites Virais. (2014). Manual Técnico para o Diagnóstico da Infecção pelo HIV. Brasília.

Ungprasert, P., Permpalung, N., Srivali, N., Bischof, E. F. \& Edmonds, L. C. (2013). Pneumocystis pneumonia during primary HIV infection: a case report and review of the literature. Journal of Infection and Chemotherapy, 19 (5). 990-991.

Vilar, F. C. \& Santana, R. C. (2008). Síndrome da imunodeficiência adquirida 1 (1), 1-73. 